\title{
Alexithymia and emotional processing: a longitudinal mixed methods research
}

\author{
Ana Nunes da Silva, ${ }^{1}$ António Branco Vasco, ${ }^{1}$ Jeanne C. Watson ${ }^{2}$ \\ ${ }^{1}$ Faculty of Psychology, University of Lisbon, Portugal; ${ }^{2}$ Ontario Institute for Studies in Education, University of Toronto, Canada
}

\begin{abstract}
Alexithymia has been associated with poor outcomes in psychotherapy. This association has been attributed to a difficulty in patients processing emotions and engaging in emotional tasks. The possibility of alexithymia being modified by psychotherapy remains a topic of great debate but with little empirical research. In this study a mixed methods longitudinal design was used to better understand alexithymia, emotional processing and change process in psychotherapy. Twelve clients, five with alexithymia, were studied considering the development of alexithymia, emotional awareness, differentiation, regulation and severity of symptoms. The reliable change index was used to interpret the evolution of those emotional variables' scores for each case and thematic analysis was used to analyze individual interviews. Thematic analysis generated several themes, organized in two broad domains: i) perception of emotions and ii) description of change. The three alexithymic patients that changed in alexithymia also changed in at least one of the emotional variables - lack of emotional awareness, emotion differentiation or emotion regulation. Generally, alexithymic patients were able to accomplish change in psychotherapy although they had a tendency to focus on physical complaints, describe changes in a more rational rather than emotional way and present vaguer descriptions of their problems. These results point that alexithymia may change through therapy and reinforces that those changes are associated with improved emotional processing.
\end{abstract}

Key words: Alexithymia; Emotional awareness; Emotional differentiation; Emotion regulation; Psychotherapy.

Correspondence: Ana Nunes da Silva, Department of Cognitive Behavioral and Integrative Psychology, Faculty of Psychology, University of Lisbon, Alameda da Universidade 1649-013, Lisboa, Portugal.

Tel.:+351.939442906.

E-mail: AnaCatarinaNS@gmail.com

Contributions: ANS, ABV, JCW: conception and design; ANS: analysis; ANS, ABV: interpretation of data; ANS: writing, original draft preparation; $\mathrm{ABV}$, JCW: writing, critical review; $\mathrm{ANS}, \mathrm{ABV}$, JCW: final approval of the version to be published.

Conflict of interest: the authors declare no potential conflict of interest.

Acknowledgments: the authors are grateful to all institutions that participated in this study. We would also like to thanks Prof. Doutor David Dias Neto for being a consultant for the qualitative analysis.

Funding: the preparation of this paper was conducted during the period that the first author was supported by a FCT grant SFRH/BD/65066/2009.

Received for publication: 7 November 2017.

Revision received: 2 January 2018.

Accepted for publication: 15 January 2018.

This work is licensed under a Creative Commons Attribution NonCommercial 4.0 License (CC BY-NC 4.0).

CCopyright A.N. da Silva et al., 2018

Licensee PAGEPress, Italy

Research in Psychotherapy:

Psychopathology, Process and Outcome 2018; 21:40-54

doi:10.4081/ripppo.2018.292

\section{Introduction}

Alexithymia has been widely studied. Although initially observed in clinical settings only recently greater attention has been given to research on alexithymia in psychotherapy. Alexithymia is conceptualized as a difficulty identifying and communicating feelings, an externally-oriented thinking style and a constricted imagination and lack of fantasy (Bagby, Taylor, \& Parker, 1994; Taylor, Bagby, \& Parker, 1997). Firstly observed in the context of psychosomatic disorders, this impairment is now identified in several other pathologies, such as mood disorders (e.g., Wise, Mann, \& Hill, 1990; Zeitlan \& McNally, 1993), abuse and substance dependency (e.g., Uzun, 2003), eating disorders (e.g., Petterson, 2004), and personality disorders, such as borderline personality disorder (Zlotnick, Mattia, \& Zimmerman, 2001). It should be noted that alexithymia appears not to be a central feature of any of these disorders, but instead a related, comorbid condition (Taylor, 1984a).

Alexithymia has been associated with poor outcomes in psychotherapy (McCallum, Piper, Ogrodniczuk, \& Joyce, 2003; Leweke, Bausch, Leichsenring, Walter, \& Stingl, 2009), and has been seen as a predictor of residual symptoms after therapy (Ogrodniczuk, Piper, \& Joyce, 2004), independent of the type of therapy (McCallum et al., 2003). Most psychotherapeutic approaches assume that clients have at least some awareness of and access to their emotions. Alexithymic patients present a particular challenge, for they have difficulties regarding the very 
skills that are central in psychotherapy such as the ability to differentiate, verbalize, and discuss subjective experiences and emotions (Ogrodniczuk, Sochting, Piper, \& Joyce, 2012). Patients with high levels of alexithymia usually have difficulties in describing what they are feeling and tend to focus on their physical symptoms (Ogrodniczuk, Piper, \& Joyce, 2011). The lack of integration between affect and cognition and a tendency toward impulsive behavior characteristic of alexithymic patients have significant implications for treatment (Krystal, 1979; Taylor et al., 1997). Ogrodniczuk et al. (2004) found that difficulty identifying feelings was a significant predictor of the severity of residual depressive symptoms after successful psychotherapeutic treatment, regardless of the initial severity of depression and anxiety, the type of treatment, or the antidepressant drug prescribed. In addition, Ogrodniczuk, Piper and Joyce (2005) observed that the reaction of the therapist to the patient partially mediated difficulties in communicating feelings and externally oriented thinking in the outcome measures (symptoms and general goals). These poor outcomes may be associated with a negative view of alexithymic clients by their therapists as well as some negative feelings the therapist develops toward the patient (Ogrodniczuk et al., 2005; Swiller, 1988). This view may involve a general devaluation of clients by the therapist or the notion that they are less compatible with them. Also, the inability to convey the experiential nature of problems could impair the ability to effectively communicate with the therapist, who may be confronted with vague complaints, making it difficult to establish a plan of action (McCallum et al., 2003). Most therapist working with alexithymic patients refer feelings of boredom, and a sense of less openness of the patient, usually interacting with very short sentences or with yes/no answers. It's hypothesized that the patient uses projective identification to discharge unbearable psychic tension into the therapist whose boredom is partly a defense against this (for a review see Taylor, 1984b).

Findings also revealed that alexithymics reported more health related problems as compared to non-alexithymics and the health problems of alexithymics were likely to be an outcome of their emotion regulation difficulties, indicated by a non-significant health difference after controlling for emotion regulation (Pandey, Saxena, \& Dubey, 2011).

As mentioned earlier, alexithymia is associated with many different disorders, from depression to personality disorders but it has been under-recognized and under-diagnosed (Tacon, 2001), presenting a challenge in different clinical settings and for clinicians. However, it does not seem to differentiate among patients who chose medication, psychotherapy or no treatment, although there is a tendency for preferring group therapy, it's hypothesized that this choice enables them to be more passive that in individual therapy (Ogrodniczuk, Piper, Joyce, \& Abbass, 2009).

Although there is some research on alexithymia and psychotherapy (e.g., McCallum et al., 2003) and also alexithymia and emotional processing (for a review see Berthoz, Pouga, \& Wessa, 2011), there is a lack of research on alexithymia and emotional processing in the therapeutic context. In this sense, it is important to develop studies where a deeper understanding of the concept could be made, not only regarding emotional processing in therapy (Silva, Vasco, \& Watson, 2013), but also its evolution from both therapist and client perspectives. What are the major difficulties felt in therapy? How do emotional processing skills develop and how is change perceived? Does thinking of specific emotional processes help in psychotherapy? We have conducted a study (Silva, Vasco, \& Watson, 2017) that attempted to investigate the associations among alexithymia, emotional awareness, emotional differentiation and emotion regulation in order to identify better ways to assist alexithymic patients in psychotherapy. Structural equation modeling (SEM) was used to test a mediation model in clinical and non-clinical samples. We argue that the association between severity of symptoms and alexithymia was mediated not only by emotion dysregulation but also by emotional awareness and differentiation (Figure 1).

In this model (Figure 1) emotional awareness represents the tendency to attend to and acknowledge emo-

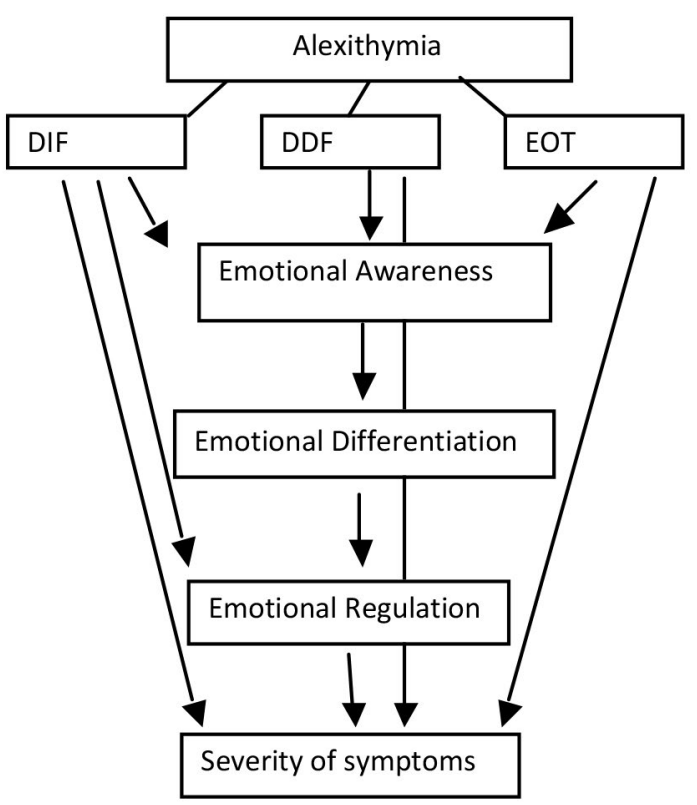

Figure 1. The influence of alexithymia on emotional processing. DIF means Difficulty identifying feelings, DDF means Difficulty describing feelings and EOT means Externally oriented thinking. In our study some variables, regarding the measures available, were reverse; being emotional awareness studied as lack of emotional awareness, and emotion regulation as limited access to emotion regulation strategies. In this figure a new association was added between DIF and Emotional Regulation regarding the SEM results. 
tions. Emotional differentiation constitutes the next step with the individual being able to recognize and assign meaning to his or her emotional experience: it is the process of mental representation of emotions, which means the symbolization and consequent expansion of the physiological reaction experienced. Finally, this would enable emotion regulation, which is the ability to understand and accept emotional experience and to engage in healthy strategies to regulate emotions, when necessary, and to engage in appropriate behavior (Silva, Vasco, \& Watson, 2017). Given this mediation model, we hypothesized that for alexithymia to change there should be a change in at least one of the mediation processes.

In the present study we wanted to observe if patients that decrease their alexithymia levels through therapy also decrease in any of the mediation variables presented at the proposed model. We were also interested in understanding how clients talk about emotions and how they perceived change process. Understanding the connection between emotional evolution in alexithymic patients in psychotherapy and their perspectives about change, may contribute to adjusting psychotherapeutic interventions to better take account of their needs. Lastly, we wanted to understand the therapists' perspective regarding intervention. To accomplish this goal a longitudinal study with a mixed method design was developed.

\section{Methods}

\section{Participants}

\section{Therapists}

This was a naturalistic study where 14 therapists from public and private practice were invited to participate and asked to invite clients starting outpatient psychotherapy. Eight therapists accepted to participate. None of the authors was a therapist in this study. The main reason advanced for non-participation was the fear of research interfering negatively with the therapeutic process. All therapists in this study were clinical psychologists. Five were cognitive behavioral therapists, one was brief psychodynamic, one integrative and one had psychoanalytic training. Six were females and two were males and they ranged in age from 25 to 43 years $(\mathrm{M}=33.13, \mathrm{SD}=6.53)$ and ranged in experience from two to 15 years $(M=7$, $\mathrm{SD}=5.50$ ).

\section{Clients}

Twenty clients were invited to participate, of whom 12 were included in this study. The remaining clients were not included, for several reasons: two declined participation; two were dropouts; one was admitted to inpatient treatment in a psychiatric hospital and no longer met the inclusion criteria; and three dropped out or finished therapy and could not be interviewed. Inclusion criteria included being 18 years of age or older and at least nine years of education. Of the 12 cases, four were complete cases, three were premature endings (the therapists considered that the goals were only partially achieved or not consolidated), four maintained their therapies beyond the $16^{\text {th }}$ session, and one dropped out after 16 sessions. There were nine females clients and three males, between the ages of 20 and 68 years $(\mathrm{M}=41.42, \mathrm{SD}=14.46)$. Of these, six $(50 \%)$ were married, four were single (33\%) and two were separated or divorced $(17 \%)$. Nine were working full time $(75 \%)$, one was unemployed $(8.3 \%)$, one was a student $(8.3 \%)$ and one was on leave of absence $(8.3 \%)$. Clients' level of education ranged from basic education ( 9 years) through graduate school: one had completed basic education $(8.3 \%)$, four had completed secondary school (33.3\%) and seven had a high degree (58.3\%). Clients were excluded from the study if they displayed cognitive deficits, presented with psychotic disorders or current drug or alcohol abuse. The main complaints were anxiety $(50 \%)$, depression $(25 \%)$, interpersonal problems $(42 \%)$, sexual problems $(8 \%)$ and social phobia $(8 \%)$. Five clients were attending psychiatric care and seven were taking psychiatric medication. Three had previous psychotherapy and two had previous psychiatric inpatient treatment.

\section{Measures \\ Alexithymia}

The Portuguese version of the Toronto Alexithymia Scale (TAS-20) was used to measure alexithymia (Bagby et al., 1994; Prazeres, Parker, \& Taylor, 2000). A 20-item, self-report measure composed of three subscales: Difficulty Identifying Feelings (DIF), Difficulty Describing Feelings (DDF), and Externally Oriented Thinking (EOT). Items are rated on a 5-point scale, ranging from 1 (strongly disagree) to 5 (strongly agree). Scores less than or equal to 51 reflect non-alexithymia, scores of 52-60 reflect possible alexithymia, and scores of 61 or greater reflect alexithymia. Analysis of the Portuguese version supported the construct validity of the three subscales, internal consistency is .79 for the total score (Prazeres et al., 2000).

\section{Emotional awareness and emotion regulation}

The Subscales Lack of Emotional Awareness and Limited Access to Emotion Regulation Strategies of the Difficulties in Emotion Regulation Scale (DERS, Gratz \& Roemer, 2004) were used to measure these concepts. The DERS is a 36-item self report measure designed to assess the complexities and clinically-relevant difficulties of emotion regulation including awareness, modulation of arousal and modulation of expression. Items are rated on a 5-point scale, ranging from 1 (Almost never 0-10\%) to 5 (Almost always 91-100\%). The Subscale Lack of Emotional Awareness consists of items reflecting the tendency to attend to and acknowledge emotions. When these items are appropriately reverse-scored, this factor reflects an 
inattention to, and lack of awareness of, emotional responses. The Portuguese adaptation showed an internal consistency of .74. The Subscale Limited Access to Emotion Regulation Strategies considers the strategies one implements when regulating emotions. It consists of items reflecting the belief that there is little that can be done to regulate emotions effectively, once an individual is upset. Internal consistency is .87 for the Portuguese version of this subscale (Vaz, Vasco, \& Greenberg, 2010).

\section{Emotional differentiation}

The Subscale Emotional Differentiation of the Portuguese version of the Range and Differentiation of Emotional Experience Scale (RDEES, Kang \& Shaver, 2004) was used to assess Emotion Differentiation. The RDEES is a 14-item self-report measure composed of two subscales: Range and Differentiation. Items are rated on a 5point scale, ranging from 1 (Does not describe me very well) to 5 (Describes me very well). The subscale Differentiation, used in this study, is constituted by eight items and assesses the ability to make subtle distinctions between similar emotions and showed an internal consistency for the Portuguese version of .82 (Vaz, 2009).

\section{Severity of symptoms}

The severity of symptoms was measured using the Portuguese version of the Brief Symptom Inventory (BSI, Degoratis, 1993; Canavarro, 1999), a reduced version of the SCL-90 with 53 items, in which participants rate the extent to which they have been disturbed in the past week by several symptoms $(0=$ not at all to $4=e x t r e m e l y)$. The BSI has nine subscales designed to assess individual symptom groups (e.g., somatization, depression, anxiety). In the comparison between cases, only the Global Severity Index (GSI) was used as a general measure of the severity of symptoms. The Portuguese adaptation was done by Canavarro (1999) showing good psychometric properties. In a sample of non-clinical participants, the GSI average was $0.48(S D=1.430)$ and test retest reliability of .79. In a clinical sample, this author obtained an average of $1.43(S D=0.943)$. A value $\geq$ to 1.7 may point to an emotion disturbance (Canavarro, 1999).

\section{Interviews}

Two different semi structured interview scripts were developed to assess therapist and client perspectives on change. To guide the interview a protocol was created. It followed the principle of starting with open questions and then closing them for issues that were considered essential. Table 1 presents the major questions and themes of the interviews for therapists and clients. Although there was a specific interest in client's emotional processing it was decided not to directly question the participants about specific processes, namely emotional awareness and emotional differentiation. We were more interested in whether they spontaneously referred to those processes when they spoke about change rather than superimposing a specific theory regarding those processes.

\section{Procedure}

The eight therapists that agreed to participate invited clients starting outpatient psychotherapy to participate. This invitation was made before the first session and if the client accepted, both client and therapist signed a written consent, were assured of confidentiality and that they could leave the study at any point without interference with therapy. The outcome measures were given at the first and eighth session and then at the end of therapy or at the sixteenth session if therapy continued (Tables 2 and 3 ). The interview was conducted with all participants shortly after psychotherapy ended or after the sixteenth session. All the interviews took place in a setting chosen by the participants, which was in most cases the hospital or clinic where therapy took place and in some cases the first author's university. The first author of the study conducted all interviews. Participants were assured of confidentiality and permission was asked to audiotape the interviews. All participants agreed to the recording.

\section{Data analysis}

Cases were grouped considering the initial level of alexithymia (alexithimic $v s$ non alexithymic) and the outcome (good $v s$ poor). Regarding the TAS-20, scores less than 52 reflects non-alexithymia, scores of 52-60 reflect possible alexithymia, and scores of 61 or greater reflect alexithymia. We chose to merge the cases with possible alexithymia and alexithymia in one group, since the two clients identified with possible alexithymia presented scores above the middle cut off point, although they are identified as can be seen in Tables 2 and 3. Concerning the outcome, both the reliable change index (RCI) and the client's perspective were taken into account. Although symptom self report measures are a customary way to measure outcome, considering that some participants started with a GSI value inferior to the RCI for the BSI, the client's perspective on change was also considered to define the outcome status. The RCI (Christensen \& Mendoza, 1986; Jacobson \& Truax, 1991; Jacobson, Follette, \& Revenstorf, 1984) can be used to compare pre-post results of psychotherapy, taking into account the standard error of measurement. In the present study we used the adaptation by Evans, Margison and Barkham (1998), which provides the RCI below which $5 \%$ of the difference may be due to error. This formula takes into account the reliability and standard deviation of the instrument. The data used to calculate the RCI came from the original Portuguese studies for all measures. The RCI for BSI was 0.89 and for TAS-20 was 12.70. A case was considered as good outcome if there was a change at least of 0.89 at BSI and the client 
reported feeling better. For alexithymic group it was as well considered a change at the TAS-20 of at least 12.70 . The RCI was also used to evaluate the evolution of the other studied variables but those variables were not taken into consideration for the formation of groups. The RCI for lack of emotional awareness was 5.94, the RCI for emotional differentiation was 9, and the RCI for limited access to emotion regulation strategies was 7.22. The RCI for TAS's subscales was 7.19 for difficulty identifying feelings, 6.92 for difficulty describing feelings and 7.87 for externally oriented thinking.

A concurrent triangulation design was used (Hanson, Creswell, Clark, Petska, \& Creswell, 2005). First it was observed how the emotion processes previously shown to mediate the relationship between alexithymia and symptoms severity (Silva, Vasco, \& Watson, 2017) would evolve according to the self-report measures. Then the interviews were explored using thematic analysis (Braun \& Clarke, 2006). Each interview was transcribed and the transcript was read and reread. Three questions guided the analysis: How did client perceive and talk about emotions? What was their perception of change? How did par- ticipants perceive the change process? The results were used to augment and cross validate the quantitative data.

When analyzing the interviews, we wanted to stay as close to the informant's concrete and contextually anchored experience as possible, while exploring their own views of what felt significant in the therapeutic process (Elliot \& Shapiro, 1992). Passages from the transcripts were sorted into categories based on a list of significant topics: perception of emotions, perception of change and how change occurred. Our goal was to identify themes that may differentiate alexithymic and non-alexithymic cases. The narrative account contains relevant extracts in the participants' own words, not only to enable the reader to assess the pertinence of the interpretations, but also to retain the voice of the participant's personal experience.

Three peer debriefing audits were arranged to validate the procedure (Lincoln \& Guba, 1986). One independent researcher was invited to analyze the process of analysis. This researcher was not involved in any part of the research but was familiar with the methodologies used in the qualitative analysis.

Table 1. Brief versions of the scripts of the therapist and client interview protocol.

\begin{tabular}{l}
\hline \multicolumn{1}{c}{ Question \& Goal } \\
\hline Brief version of the script of the therapist interview protocol \\
\hline - Could you tell me a bit about this client? [Warm-up question] \\
\hline $1-$ What were the most meaningful aspects of the therapy? [Identification of central themes or processes] \\
\hline \begin{tabular}{l}
$3-$ How did change occur in psychotherapy? [Mode/Type of change] \\
\hline $4-$ How did emotional change occur? [Specific change on emotional processing]
\end{tabular} \\
\hline $5-$ What, in the client, facilitated change? [Client processes relevant in change] \\
\hline $6-$ What, in the client, made change harder? \\
\hline $7-$ Did you consider that this client had some indicator of personality disorder? \\
\hline - Did you consider that this client had some alexithymic characteristics? \\
\hline - Did you feel the need for any kind of supervision in this case? \\
\hline 10 - Is there anything you would like to add?
\end{tabular}

\section{Brief version of the script of the patient interview protocol}

0 - Could you tell how was it for you being in therapy? Was it the first time? [Warm-up question]

1 - What were the most meaningful aspects of the therapy? [Identification of central themes or processes]

2 - How did change occur in psychotherapy? [Mode/Type of change]

3 - What do you feel you have gained from being in therapy? [perception on gains concerning therapy $v s$ changes outside]

4 - How did emotional change occur? [Specific change on emotional processing]

5 - How did you regulate emotion? How do you regulate them now? [emotion regulation perception and change process]

6 - Do you consider yourself a more rational or more emotional person?

7 - How was the therapeutic alliance? How did it evolve? [Characterization of therapeutic alliance thought therapy]

8 - Is there anything else you would like to add or ask me? 


\section{Results}

As expected, from the results in Tables 2 and 3, all patients that started therapy with a high level of alexithymia, when there was a significant decrease in alexithymia there was also a significant increase in at least one of the mediation variables - awareness, differentiation or regulation. This was verified in cases 4,8 and 13 , and from the assessment of the different alexithymia factors it is observe a decrease in difficulty identifying feelings and difficulty describing feelings but not in externally oriented thinking. This was not observed in case 5, that will be further explored, and case 11 that had a bad outcome. When observing the results for the good outcome non-alexithymic patients no significant changes were observed in any of the mediation variables. Considering the different factors of alexithymia only case 7 showed a significant increase, at the middle of therapy, in difficulty identifying feelings, but this was not significant by the end of therapy. Next, data concerning the thematic analysis will be present to better understand these results and also point some differences between narratives.

\section{Thematic analysis}

Thematic analysis generated several themes and subthemes, organized in two broad domains: i) Perception of emotional processing and emotional experience; and ii) Change Process (Table 4).

\section{Domain 1. Perception of emotional processing and emotional experience}

How did alexithymic clients perceive their emotional experience? What was different between the alexithymic and non-alexithymic cases?

\section{Emotional description}

Alexithymic clients presented emotional descriptions more focused on physical complaints (sub-theme: physical description of emotions). This contrasted with the emotional descriptions of non-alexithymic clients, who described emotions or emotional discomfort in reaction/relation to something/someone. For example, client 4 was an alexithymic client who, although able to talk and disclose about several events in her life, showed a tendency to respond with yes/no questions and when asked about emotional changes focused on the rational aspects and described her emotions using physical terms.

Interviewer: And in terms of feelings? You described anguish as the most present feeling, what replaced it? How do you feel that emotion evolved? You told me that Dr. THERAPIST gave you some ideas that you would go home and think about...

Patient: Yes (...)

Interviewer: How was it inside?

Patient: At first it was a squeeze, but I think that is also passing...It's already more...I released this tension that I had, that anguish at...at...chest anguish, I think that had pass now, at least if not completely at least $95 \%$. Alexithymic good outcome Patient 4 interview - 9'10"

Subtheme: Physical description of emotions

This was also observed in client 8 , a possible alexithymic that also presented some tendency to focus on physical aspects when talking about emotions:

Table 2. Evolution of the cases considering the reliable change index (RCI).

\begin{tabular}{|c|c|c|c|c|c|c|c|c|c|c|c|c|c|c|c|c|c|}
\hline \multirow[b]{2}{*}{ Session } & & \multirow[t]{2}{*}{$\sqrt{2}$} & \multicolumn{3}{|c|}{$\begin{array}{c}\text { Alexithymia } \\
\text { (TAS-20) } \\
\text { RCI=12.7 }\end{array}$} & \multicolumn{3}{|c|}{$\begin{array}{c}\text { Symptoms } \\
\text { severity (BSI) } \\
\text { RCI }=0.89\end{array}$} & \multicolumn{3}{|c|}{$\begin{array}{c}\text { Awareness } \\
\text { (lack) } \\
\text { RCI }=5.94\end{array}$} & \multicolumn{3}{|c|}{$\begin{array}{l}\text { Differentiation } \\
\qquad \mathrm{RCI}=9\end{array}$} & \multicolumn{3}{|c|}{$\begin{array}{c}\text { Regulation } \\
\text { (limited) } \\
\text { RCI=7.22 }\end{array}$} \\
\hline & & & $1^{\text {st }}$ & $8^{\text {th }}$ & $16^{\text {th }} /$ End & $1^{\text {st }}$ & $8^{\text {th }}$ & $16^{\text {th }} /$ End & $1^{\text {st }}$ & $8^{\text {th }}$ & $16^{\text {th }} /$ End & $1^{\text {st }}$ & $8^{\text {th }}$ & $16^{\text {th }} /$ End & $1^{\text {st }}$ & $8^{\text {th }}$ & $16^{\mathrm{Th}} /$ End \\
\hline \multirow[t]{10}{*}{ Good outcome } & Alexithymic & 4 Complete & 76 & 67 & $58^{*}$ & 2,26 & 1,92 & $0,92 *$ & 27 & 22 & $18^{*}$ & 26 & 31 & 34 & 28 & 27 & 24 \\
\hline & (possible & 5 Ongoing & 64 & 53 & 62 & 3,15 & $2,15^{*}$ & $2,19 *$ & 15 & 14 & 19 & 36 & $25^{*}$ & 30 & 33 & 39 & 37 \\
\hline & alexithymia & 8 Ongoing & 60 & $40 *$ & $42 *$ & 2,38 & $0,32^{*}$ & $0,38^{*}$ & 17 & 14 & $11^{*}$ & 34 & $43 *$ & 37 & 22 & $11 *$ & $9^{*}$ \\
\hline & $51-60)$ & $\begin{array}{l}13 \text { Premature } \\
\text { Ending }\end{array}$ & 56 & $35^{*}$ & & 1,25 & 0,7 & & 16 & 19 & & 40 & 32 & & 23 & $8^{*}$ & \\
\hline & Non & 1 Complete & 46 & 58 & & 1,43 & $0,13^{*}$ & & 20 & $11^{*}$ & & 29 & $38^{*}$ & & 22 & $31 *$ & \\
\hline & alexithymic & 3 Complete & 43 & 41 & 36 & 0,77 & 0,38 & 0,25 & 15 & 14 & 16 & 18 & 19 & 16 & 9 & 13 & 10 \\
\hline & & 6 Ongoing & 42 & 31 & 39 & 1,15 & $0,11^{*}$ & 0,36 & 14 & 11 & 15 & 37 & 40 & 42 & 18 & 16 & 13 \\
\hline & & 7 Complete & 34 & 48 & 39 & 0,66 & 0,83 & 0,45 & 19 & 19 & 17 & 38 & 34 & 37 & 23 & 24 & 22 \\
\hline & & $\begin{array}{l}9 \text { Premature } \\
\text { Ending }\end{array}$ & 41 & 36 & & 0,75 & 0,53 & & 7 & 9 & & 40 & 48 & & 28 & 25 & \\
\hline & & 10 Ongoing & 31 & 38 & 39 & 1,02 & 0,36 & 0,62 & 12 & 12 & 9 & 45 & 52 & 53 & 21 & 18 & 21 \\
\hline \multirow[t]{2}{*}{ Bad outcome } & Alexithymic & 11 Dropout & 67 & 64 & 72 & 0,98 & 0,7 & 0,66 & 22 & 23 & 24 & 11 & 17 & 17 & 19 & 22 & $27^{*}$ \\
\hline & $\begin{array}{l}\text { Non } \\
\text { alexithymic }\end{array}$ & 2 Ongoing & 50 & 52 & 46 & 0,87 & 0,7 & 0,92 & 18 & 19 & 17 & 28 & 29 & 33 & 19 & 17 & 21 \\
\hline
\end{tabular}

* Significant change considering the RCI when compared with the first session value. 
Interviewer: And how was it, how would you regulate or deal with that sadness?

Patient: I didn't, I let myself go. (...) in all aspects. I lost weight, 10kgs, I got sick. Professionally...the only thing that encouraged me to be a different person was my profession. I walked into my professional role and I was someone else. I held on to it, so as not to think about those issues, but even then people noticed the difference. So... the sadness possessed me completely.

Alexithymic good outcome Patient 8 interview - 11'23"

Subtheme: Physical description of emotions

On the other hand, non-alexithymic good outcome cases seemed to be focused on specific problems when referring to emotions. In these excerpts it can also be seen the contrasts with the previous examples, referring the clients more emotional words and presenting an integrated narrative regarding the need for therapy and specific events.

I was very sad, very, very sad, very depressed, very sad about my life not taking action, a passive life, sometimes I was a very sad person, though I had moment of joy in my life, but I was a sad person and very submissive, In moments of trouble I was always the same way, always accepting everything...very, very sad. (...) Before I would feel deeply sad, now I try to think of other things, I try to think of other things in life and do not give much importance to the quarrels of my FAMILY MEMBER, do not give much importance. I'm a little upset but it is not that deep sadness, the feeling of abandonment that I had...no! I try to think of other things, and grab on to my children. If my FAMILY MEMBER is upset I'll take a walk with the kids, go out to lunch.

Non-alexithymic good outcome Patient 3 interview 2'53"

Subtheme: Emotions described in association to a specific problem/life event

...that situation triggered a series of fears. Fears about my professional activity, that something could go bad, situations... anything that could shake my professional structure mainly. I think the cancer triggered a series of fear, shake my structures and so I ended up creating a series of fears and anxieties in relation to everything else that was around me. And therapy ended up getting dispels this situation. (...) Initially I was not able to manage them [emotions], they possessed me (...)

Non-alexithymic good outcome Patient 7 interview 3'30"

Subtheme: Emotions described in association to a specific problem/life event

\section{Awareness}

Regarding awareness, two aspects were mentioned: the awareness of avoiding emotions and the awareness of not expressing emotions. Case 10 and Case 2, both ongoing cases, are examples of cases that presented awareness of their avoidance of emotional experiencing something that was not explicitly described by the alexithymic cases in the study.

Patient: I am aware of the importance of emotional life. And I think I have some awareness of my emotional life. Probably not as much as I should have and especially I do not live it.

Table 3. Evolution of the cases considering the reliable change index (RCI) during different sessions.

\begin{tabular}{|c|c|c|c|c|c|c|c|c|c|c|c|}
\hline \multirow{2}{*}{$\begin{array}{l}\text { Variable } \\
\text { Session }\end{array}$} & & \multirow[t]{2}{*}{$\sqrt{2}$} & \multicolumn{3}{|c|}{$\begin{array}{c}\text { DIF } \\
\text { RCI }=7.19\end{array}$} & \multicolumn{3}{|c|}{$\begin{array}{c}\text { DDF } \\
\text { RCI }=6.92\end{array}$} & \multicolumn{3}{|c|}{$\begin{array}{c}\text { EOT } \\
\text { RCI }=7.87\end{array}$} \\
\hline & & & $1^{\text {st }}$ & $8^{\text {th }}$ & $16^{\text {th }} /$ End & $1^{\text {st }}$ & $8^{\text {th }}$ & $16^{\text {th }} /$ End & $1^{\text {st }}$ & $8^{\text {th }}$ & $16^{\text {th }} /$ End \\
\hline \multirow[t]{11}{*}{ Good outcome } & Alexithymic & 4 Complete & 31 & 25 & $23 *$ & 21 & 19 & $14^{*}$ & 24 & 23 & 21 \\
\hline & (possible & 5 Ongoing & 27 & 30 & 27 & 15 & 9 & 13 & 22 & $14^{*}$ & 22 \\
\hline & alexithymia & 8 Ongoing & 28 & $13 *$ & $20 *$ & 16 & 10 & $7 *$ & 16 & 17 & 15 \\
\hline & $51-60)$ & $\begin{array}{l}13 \text { Premature } \\
\text { Ending }\end{array}$ & 13 & 9 & & 25 & $13 *$ & & 18 & 13 & \\
\hline & Non & 1 Complete & 13 & $20 *$ & & 6 & $15^{*}$ & & 27 & 23 & \\
\hline & alexithymic & 3 Complete & 14 & 14 & 10 & 9 & 8 & 6 & 20 & 19 & 20 \\
\hline & & 6 Ongoing & 14 & 9 & 14 & 13 & 8 & 11 & 15 & 14 & 14 \\
\hline & & 7 Complete & 9 & $16^{*}$ & 14 & 6 & 8 & 7 & 19 & 24 & 19 \\
\hline & & 9 Premature & 10 & 10 & & 12 & 9 & & 19 & 17 & \\
\hline & & Ending & & & & & & & & & \\
\hline & & 10 Ongoing & 11 & 16 & 12 & 8 & 9 & 13 & 12 & 13 & 14 \\
\hline \multirow[t]{2}{*}{ Bad outcome } & Alexithymic & 11 Dropout & 20 & 17 & 24 & 25 & 23 & 23 & 22 & 24 & 25 \\
\hline & $\begin{array}{l}\text { Non } \\
\text { alexithymic }\end{array}$ & 2 Ongoing & 13 & 16 & 15 & 16 & 15 & 13 & 21 & 21 & 18 \\
\hline
\end{tabular}

*Significant change considering the RCI when compared with the first session value. 
Interviewer: So it's a more rational sense of the thing and not so experiential?

Patient: Not so experiential.

Interviewer: Almost like 'I know I'm sad or anything, but I am not living my sorrow'.

Patient: I can...this kind of detachment is a way of defending myself.

Non alexithymic good outcome Patient 10 interview -19 '38"

Sub-theme: Awareness of avoidance

I don't know if it was the physical part along with the psychological part... and I always had refuge...I always had serious problems, very serious problems at home, but always refuge at my work. When I was working I forgot the problems.

Non alexithymic bad outcome Patient 2 interview 9'30"

Subtheme: Awareness of avoidance

Case 11, an alexithymic bad outcome, presented some awareness of his difficulties regarding emotions but they seemed ego sintonic. It was difficult to identify emotional descriptions in this patient's interview. From the next excerpt it is visible that he tended to respond with yes and no answers, making the interactions less fluid than in other interviews. Nevertheless, he was aware of not expressing emotions.

Interviewer: You feel like a person who easily expresses emotions?

Patient: No.
Interviewer: To show it...

Patient: No.

Interviewer: You were aware of this?

Patient: Yes.

Interviewer: Even before therapy?

Patient: Yeah.

Interviewer: And how is it... is something that PATIENT would liked to be different? Was it always like this?

Patient: It was always like this, I'm not seeing myself changing in any way, so...

Interviewer: Do you feel this reflects on the way people relate to you, not expressing emotions? On how you relate to yourself? If you could choose, would you like to be more expressive?

Patient: If I could choose, I do not think so. I would rather be as I am. But from what I've learned I think it would be good to change but...I do not see how. Alexithymic bad outcome Patient 11 interview - 5'18"

Subtheme: Awareness of not expressing emotions

Case 13 , a possible alexithymic patient also showed awareness of not expressing emotions:

Interviewer: PATIENT feel you are a person who easily expresses emotions?

Patient: No. I'm not. I'm not, it's hard, just with one or two close friends, I do not tell my problems to anyone, only to medical figures.

Possible Alexithymic good outcome Patient 13

Interview - 11'33'"

Subtheme: Awareness of not expressing emotions

Table 4. Summary of domains, themes and subthemes reported by participants.

\begin{tabular}{|c|c|}
\hline & Theme and Subtheme \\
\hline \multicolumn{2}{|c|}{ Domain 1. Perception of emotional processing and emotional experience } \\
\hline Emotional description & $\begin{array}{l}\text { Physical description of emotions } \\
\text { Emotions described in association to a specific problem/life event }\end{array}$ \\
\hline Awareness & $\begin{array}{l}\text { Awareness of avoidance } \\
\text { Awareness of not expressing emotions }\end{array}$ \\
\hline Emotional understanding & $\begin{array}{l}\text { Incomprehension } \\
\text { Giving meaning to experience }\end{array}$ \\
\hline \multicolumn{2}{|l|}{ Domain 2. Change process } \\
\hline Description of problems & $\begin{array}{l}\text { Unarticulated formulation of problems or goals } \\
\text { Integrated formulation of problems and goals }\end{array}$ \\
\hline Description of change & $\begin{array}{l}\text { Vague description of change } \\
\text { Description of specific change(s) }\end{array}$ \\
\hline Affective change focus & $\begin{array}{l}\text { External focus } \\
\text { Intra or/and interpersonal focus }\end{array}$ \\
\hline Process of change interventions & $\begin{array}{l}\text { Linking emotions to events/needs } \\
\text { Gaining awareness of relational patterns } \\
\text { Gaining access to new perspectives } \\
\text { Difficulty coaching emotional awareness and emotional differentiation }\end{array}$ \\
\hline
\end{tabular}


The non-alexithymic patients in this study showed awareness of emotional experience, has may be seen in the theme Emotional description. Non-alexithymic clients when referring to emotional dysregulation, referred more emotional words and described emotions associated with specific situations, which is observe in the sub-theme Emotions described in association to a specific problem/life event. Alexithymic patients also showed awareness of emotional experience, although described as symptoms (see theme Emotional description). Nevertheless, awareness of avoiding emotions was not an aspect that emerged from the alexithymic cases' narratives.

\section{Emotional understanding}

Concerning emotional understanding, two main subthemes were observed: Incomprehension and Giving meaning to experience. Client 5, an ongoing good outcome alexithymic, during the interview when referring to emotions was more focused on symptoms and she explicitly expressed some incomprehension of them:

I do not know, sometimes I feel very satisfied, but it's very complicated to explain because sometimes there is just a mixture offeelings that I can't quite understand. That is: I feel like I'm progressing in some things but then still have periods where it goes all downhill. And the more I try to act according to what I've learned here, with the work I have done here in the sessions - and it helps me, helps me to try to balance things, which I was not able to do, is a fact-but sometimes I cannot. Sometimes I come here to Dr. TERAPHIST 'Look I am three steps back!'

Alexithymic good outcome Patient 5 Interview $18^{\prime} 40^{\prime \prime}$

Subtheme: Emotional incomprehension

Several patients referred giving meaning to experience - meaning understanding why they felt in a certain way as something associated with emotional comprehension. This category emerged associated to the change process, especially in alexithymic patients:

I guess I was too much involved with some family problems and had to get that weight off my back, every person makes their choices and I cannot influence everyone in my family to follow the best way. I think that's one of the important points. I had to let go of the responsibility I felt towards my family. (...) and to understand why I felt some things and the connection with my anxiety and fears.

Possible alexithymic good outcome Patient 13 Interview - 2'40"

Subtheme: Giving meaning to experience

First, gaining awareness [most important aspect of the therapeutic process]. To become aware of things that makes me...ah...revolt. I was a very angry person. And... and I tried to hide some things and tried not to think about some things and... and went forward not looking back...I'm the greatest and I can take it all, and it is not quite like that...I think people have to go back...back off a bit, even look at the past, gain awareness of what happened, accept, and then move on.

Possible alexithymic good outcome Patient 8 interview - 2'09'

Subtheme: Giving meaning to experience

\section{Domain 2. Change process}

In this domain several categories emerge, which were organized in three main themes: i) descriptions of problems; ii) description of change; iii) affective focus (Table 4).

\section{Description of problems}

Patients in this study that started therapy with alexithymia, showed a tendency to speak more vaguely, maybe because they expressed more complaints, and focused on rational aspects. For example, Case 4, an alexithymic patient, although showing significant emotional changes (Tables 2 and 3), described them more associated with concrete events or situations rather than with her emotional processing. She showed awareness of change by recognizing she was doing things differently but not with a specific theory regarding change. Also, she tended to report several problems with some dispersed descriptions:

For me I think it [psychotherapy] was very important because I had never been in therapy and I had several problems: my alcoholic FAMILY MEMBER_1, my FAMILY MEMBER_2 committed suicide, my FAMILY $M E M B E R \_3$ who died in my presence...I had a person to take care of FAMILY MEMBER_3 because she was 94 years and I always had a person... from a certain age was a person with her. And it was a Saturday and it was I that was there and FAMILY MEMBER_3 fell...It was very complicated, I think all I had...helped me a lot to overcome because I felt very guilty of my FAMILY MEMBER_2 death and my FAMILY MEMBER_3. But I always thought that FAMILY MEMBER_2 committed suicide, now I am not so sure...

Alexithymic good outcome Patient 4 interview - 0'10"

Subtheme: Unarticulated formulation of problems or goals

Another example of this difficulty in formulating an articulated goal is given by Client 11 , alexithymic, that described no changes, and when the interviewer tried to explore what he expected from therapy, he seemed confuse and did not know how to respond:

Interviewer: If the PATIENT could say 'what I wanted from therapy was'... The psychiatrist counseled you to do therapy but when PATIENT came, 
what did you want to change, what would you liked to have happen that has not happened yet?

Patient: I honestly can't say [deep breath]...I do not know.

Alexithymic bad outcome Patient 11 interview - 2'30"

Subtheme: Unarticulated formulation of problems or goals

When analyzing non-alexithymic clients' narratives, they usually described specific goals or problems:

What brought me here was... well I do not know how to explain...was a need to change some things in my life and in my way of being in relation with my FAMILY MEMBER more specifically and with certain aspects of life, I had difficulty saying no, was very passive, said yes to everything, was afraid to harm myself... and this was more...how shall I say, one way of seeing life differently and say no and get angry, and change the relationship with my FAMILY MEMBER.

Non alexithymic good outcome Patient 3 interview 0'20"

Subtheme: Integrated formulation of problems and goals

Strictly speaking, strictly speaking what I wanted was...it was...I do not know if the term is appropriate: validate. Maybe not, it is too strong, too abstract...but somehow confirm or discuss with a third person certain facts of a relationship that I keep and that is very problematic and realize if it was I that was seeing bad things on it or not.

Non alexithymic good outcome Patient 6 interview 0'50"

Subtheme: Integrated formulation of problems and goals

The major goal was to free myself of some fears and anxieties I had. Mainly from some repetitive behaviors associated with those anxieties, those fears. Triggered eventually...caused or triggered by a traumatic situation...I had cancer

Non alexithymic good outcome Patient 7 interview 0'48"

Subtheme: Integrated formulation of problems and goals

\section{Description of change}

In this study, a narrative more vague and focused on rational changes was associated with alexithymia. For example, in the interview with client 4 , an alexithymic that showed a decrease in lack of emotion awareness (Tables 2 and 3), there was not a specific excerpt where that change was captured, being her descriptions more associated with rational changes.
Interviewer: And how would you describe the evolution of that anguish, how did it changed?

Patient: I talked to the THERAPIST, he talked and I would think, and then I said 'maybe he is right', first I thought he wasn't right, but we...I believe we have a good relationship and I would agree with him in the session but then I would come outside and question if it was really like that, but things evolved and I believe he is right in his words and I have been feeling freer. And moreover I even told the Dr., last time I was there...I...everyone...but specially us from SOUTHERN PART OF THE COUNTRY have a bit the cult of the dead and I usually go to the cemetery. (...) And last time my sister said 'aren't we going to the cemetery?' 'No. To the cemetery, what for?' And then I thought...then I told Dr.THERAPIST, in other circumstances I would not have said that because it was Christmas...I had to go to the cemetery to my father's grave, to my mother's grave... This year I said 'No. For what?!'

Alexithymic good outcome Patient 4 interview - 7'10" Subtheme: Vague description of change

By contrast, the next excerpt shows a non-alexithymic client, that have a narrative more integrated, describing a specific change influenced by therapy:

We began by establishing a practical plan of situations that I did in my day-to-day who were obsessive. I.e. option to go to the post office to see if any problems came in the mail: a fine... anything associated with my professional life. I had an almost daily obsession of going to the post office, i.e. every morning was anxiously waiting for the problems to arrive by mail. So it was a practical process in order to eliminate this habit. And by eliminating this, other problems probably were also dissipating. Fears, anxieties were...disappeared.

Non-alexithymic good outcome Patient 7 interview 4'28"

Subtheme: Description of a specific change

\section{Affective change focus}

Regarding the affective focus, two subthemes emerge: an external focus and an intra or/and interpersonal focus. An external focus, meant that the client was more focused on external change, and an intra o/and interpersonal focus meant that the client was more focused on his/her internal changes or changes in the way he/she related to others. The first emerged mainly in narratives of clients that had a bad outcome or prematurely ended therapy. For example, changes in client 13 , a possible alexithymic, seemed more circumstantial to changes in the outside.

Since I had no job I only lived for those problems and felt I had no way to help my family, but the situa- 
tion turned around, the problems solved themselves and I think I was also improving due to the problems' resolution.

Possible alexithymic good outcome Patient 13 Interview $-7^{\prime} 07^{\prime \prime}$

Subtheme: External focus

Case 2, a non alexithymic bad outcome, also showed an external focus. When asked about her changes in therapy:

That's what I can't picture, that there had been an evolution on those problems, those that make me anguish, the problems still there...

Non alexithymic good outcome Patient 2 interview 22 ' $56^{\prime \prime}$

Subtheme: External focus

On the other hand, client 8 , a possible alexithymic case good outcome, showed this intra and interpersonal focus:

One of the things that most impressed me is being able to identify what causes me to have an emotional breakdown. Identify both the external and the internal patterns and knowing my own patterns; what I do to cause this. Formerly, maybe I would only blame the others (...) Choose, know how to choose, know that I have options and make rational ones, thinking, writing, which...if I do this what will happen? (...) Then I remember a few phrases of the questionnaire 'I know clearly identify the external and internal factor'...' At first 'What?! I didn't know' Maybe I choose 'no, never, rarely' and now I am fine, and that was one of the items that I was there a long time thinking...

Possible alexithymic good outcome Patient 8 interview - 7'00"

Subtheme: Intra or interpersonal focus

In this case, change went beyond pragmatic changes. It may represent an example of how alexithymia can be changed in therapy. It seems a reflected process; she became aware of her functioning. And even if this awareness was more cognitive, being able to better understand some of her patterns, as she mentioned, helped her make sense of experience. This was also observed in other alexithymic patient:

One of the things I've learned, have being learning in the sessions, is that there are many things that belong to our past, to our growth and the formation of our personality that we think - and I'm talking about us in common sense, right? - We think it doesn't, but often later it reflects in our behavior. I used to say 'I had a normal childhood, so I'm a normal person'- is common sense, I say. And sometimes there're certain relationships and intersections between things that when well analyzed make sense. (...) And they are often issues that have nothing to do with each other directly, but eventually are all related to one another, is not it?

Alexithymic good outcome Patient 5 Interview $14^{\prime} 05^{\prime \prime}$

Subtheme: Intra or interpersonal focus

This was also observed in non-alexithymic clients' narratives:

I feel it changed some relationship problems, but they have not been totally resolved [laughter] but I think the fact that I have changed...because I have changed, and I am still changing, because it is not in six months that a person changes a life, I feel stronger, I feel more confident in myself, I look for a way to be happier, try taking attitudes...I think more in myself, having the most correct attitudes in my life to make me feel good. I always thought first for the good of others and never thought of me.

Non alexithymic good outcome Patient 3 interview 3'30"

Subtheme: Intra or interpersonal focus

She [therapist] allowed me to try new approaches, to see things from another perspective to see if we could in fact overcame some problems...or try the relationship to overcome some problems with a different approach on my part, and it was interesting but did not achieve greater effects because the situation is what it is and I alone cannot change the course of events, I cannot change people, the person in question...so...but...it was still indeed an interesting experience. (...) It was on the basis of what was happening and how I lived it, how I felt and how I could somehow circumvent or address the situation otherwise. Maybe in the way, I think so, win...regain some self-esteem.

Non alexithymic good outcome Patient 6 interview 3'11"

Subtheme: Intra or interpersonal focus

\section{Process of change interventions}

Four subthemes emerge when exploring interventions from the therapists' perspective: i) Linking emotions to events/needs; ii) Gaining awareness of relational patterns; iii) Gaining access to new perspectives; iv) Difficulty coaching emotional awareness and emotional differentiation.

There seems to be a match between the affective focus of the client and the description of change. In cases where the client described a focus on intra or interpersonal, the therapist described change focused on creating an integrated narrative by gaining awareness of relational patterns and also linking emotions to events/needs. This is observed, for example, in the interviews from the therapists of cases 8 and 5 : 
Okay, what happened in therapy? She begins to be aware of the dysfunctional way she and her parents relate and somehow also gained some awareness about the role of the relationship with her boyfriend in her life and what was right and what was wrong in it.

Possible alexithymic good outcome Therapist 8 interview -3 ' $15^{\prime \prime}$

Subtheme: Gaining awareness of relational patterns

Begins to be quite affirmative to her mother and this begins to have a secondary effect that is, the father is no longer seen as the great tyrant. (...) She felt a lot of guilt towards her mother (...) because it felt like she was not giving support to her mother (...) And so she made some changes in order to not respond due to this guilty, but even until the end she still felt that guilt, right? Therefore, this shows that it is a partial change.

Possible alexithymic good outcome Therapist 8 interview -4 '25"

Subtheme: Linking emotions to events/needs

Initially I figured that being in an emotional situation where she did not realize why some things happen, she had to learn how to think about it, so she had to have a theory about herself, to help her relate to what happens and to why it happens. Because as a rational person, and in such patients it is even more important because it - not in a closed mode - but there are patients who have this...this need and this need can be used on their behalf. They perceive better, obviously not in an absolute way 'now I realize everything'.

Alexithymic good outcome Therapist 5 Interview 14 '23"

Subtheme: Linking emotions to events/needs

With narratives with more external focus the therapists referred more rational interventions, as for example Case 4:

I quite honestly think it was the work of cognitive reframing, to explore alternatives because there was a very large component of guilt in grief and it was possible to work from a more cognitive standpoint. She engaged in some behavioral experiments and I think it was positive because it clearly opened the range of perspectives and I think it is a case where the cognitive work results in a very visible way.

Alexithymic good outcome Therapist 4 interview -

2'48"

Subtheme: Gaining access to new perspectives

Complementarily, linking emotions to events and gaining awareness of interactional patterns was something that the therapist tried to achieve with client 11, a bad outcome alexithymic case. But the therapist considered that the patient needed to be aware of his emotions and be able to make distinctions between emotions and talk about them in order to be able to do that:

(...) if I ask him how he is, he cannot make differentiations, for example. Varies between feeling good or feeling bad, basically. Being that felling good does not exactly means feeling good neither feeling bad means...Then when I try to explore the emotional significance of specific things, for example, he goes play cards with some friends, for example, friends have a party afterwards and he prefers not to stay. And when I try to explore the emotional experience it is extremely difficult. It is as if he had not exactly access to it. And then it is very difficult to explore things in therapeutic terms. Almost... what I've been doing with him is using a didactic logic, in the sense that I pull him to look inside and try to find a language...but often, just for you to get an idea, often it's like I am guessing the type of emotional reactions that people can have in these situations, I try to explore with him the various possibilities of emotions, try to help him identify the one that has more to do with him and then try to elaborate deeper, etc. Almost in a very didactic and very constructive logic, brick by brick. Obviously this takes time.

Alexithymic bad outcome Therapist 11 interview -

2'50"

Subtheme: Difficulty coaching awareness and emotional differentiation

\section{Cases that challenge our model}

Concerning the qualitative data, cases 1 and 5 (Table 4) may challenge our model. Case 1 was a complete good outcome case where a significant decrease in symptoms was observed. Although not significant, by one point, she increased her level of alexithymia from a non-alexithymic to a possible alexithymic level. She decreased significantly in lack of emotional awareness and increased in differentiation what is not consistent with an increase in alexithymia. A possible explanation could be the increasing in limited access of emotional regulation strategies that is directly related to alexithymia. Nevertheless, from the interview it is explicit that therapy developed from a focus on the exterior to a focus on herself, her thoughts and feelings. And the patient gained in emotional repertoire and differentiation as well as tolerating emotion dysregulation.

.... first she stopped talking about others and started talking about herself; then started talking about things and how she resolved them, that she had not done it in the same way, right? And starts to observe the results of what she has done differently. Then there's a time when she realizes that she can choose: she can choose to precipitate again, to get angry again, to wait, to calm down first, so she...now I understand... because first she just starts to do differently and then 
realizes that she does not have to let go how she did things if she founds it appropriate.

Non alexithymic good outcome Therapist 1 interview $-15^{\prime} 19^{\prime \prime}$

Subtheme: Gaining access to new perspectives

Nevertheless she presented a narrative with similarities with the narratives of alexithymic patients, such as presenting some vague descriptions about change and also describing emotions as symptoms:

This is related with anxiety crises for about three years now. I was more anxious than usual and I had a big crisis, I even thought I was having a heart attack; the symptoms are exactly the same. And so I understood that something wasn't right. (...) The antidepressants took my appetite. And I couldn't have control of that situation. (...) Meanwhile, I had also a consultation at HOSPITAL, I enter the underground and it was...the worst of it... was...there I was having a panic attack. I wasn't able to control myself. And...that was it. From there on I took his advice. To come and ask for help (...)

Non alexithymic good outcome Patient 1 interview 0 '15"

Theme: Physical description of emotions

During those three years I always denied [the need for therapy] and things got worse and when my physician said he couldn't help and I said I didn't want to take medication and he said then lets... And I said 'no', because I thought he was sending me to a psychiatrist, 'no'. Then I came here, this was clinical psychology, I thought it was a pompous name, it had more to do with me and so... without noticing that feeling of sadness and anguish, passed.

Non alexithymic good outcome Patient 1 interview -

13 '23"

Theme: Vague description of change

The other case that may challenge our model is Case 5, an ongoing case that, at the last assessment, showed a significant decrease in severity of symptoms, although still at a clinical level (>1.7), but no improvement in alexithymia or in any of the mediation variables. This case may be contrary to our initial theorization since in session 8 there was an almost significant decrease (-11) in alexithymia, a significant decrease in severity of symptoms and at the same time a significantly worsening in emotional differentiation. Regarding the proposed model (Figure 1) it was not expected a decrease in emotional differentiation. A possible explanation is that since at that assessment she significantly decreased in externally oriented thinking (EOT) that, considering our model, is positively associated with the severity of symptoms, this decrease in symptoms could be better explained by the decrease in EOT. Being this change asso- ciated with a decrease in EOT she may still presented difficulties identifying and describing feelings which may have account for the decrease in differentiation.

\section{Discussion and Conclusions}

These results (Tables 2 and 3) seem to partially support our model (Figure 1). Generally, alexithymic cases were able to accomplish change in psychotherapy. This change seemed related to change in at least one of the emotional variables proposed in our model. This was observed in cases 4,8 and 13 . In our study, change in alexithymia occurred even when there was a significant decrease in only one of the mediation variables (or vice versa), as exemplified by Case 4 , who showed a decrease in lack of emotional awareness, and Case 13, who showed a decrease in limited access to emotion regulation strategies (Tables 2 and 3). Case 8 showed a decrease in two variables, lack of emotional awareness and limited access to emotion regulation strategies. Considering the different alexithymia factors, in our cases, changes were associated with diminish in difficulty identifying feelings and difficulty describing feelings but not in externally oriented thinking. Cases 4 and 8 decreased in both factors. Case 13 only decreased in difficulty describing feelings, but she started with levels of difficulty identifying feelings inferior to those cases. The bad outcome case with alexithymia - Case 11 - showed no decrease in alexithymia nor in symptoms' severity and he even showed a significant increasing in limited access to emotion regulation strategies.

In this study, patients starting therapy with alexithymia, even when there is a significant change, have a tendency to express emotions focused on physical complaints and describe change in a more rational rather than emotional way. Also, these patients seem to present vaguer descriptions of their problems or refer several different problems. These aspects seem to support results from previous research (McCallum et al., 2003; Ogrodniczuk et al., 2011). Although the interviews were made after therapy and some work in developing these skills may have been done, from the excerpts, it can be seen a lack of expectations or an overwhelmed posture at the beginning of treatment.

When observing the results of the good outcome nonalexithymic patients no significant changes were observed in any of the mediation variables. When referring to change, good outcome non-alexithymic cases presented specific complaints associated with conceiving their problems defined from a personal change perspective and when there were relational issues they were circumscribed to a specific person or situation. Also they were more specific and specify techniques and strategies used in therapy which made the therapeutic processes seemed more focused. The non alexithymic bad outcome case, although clearly aware of her functioning, presented more prob- 
lems and was uncertain about her therapeutic process.

It cannot be said for sure if it is alexithymia that impairs these processes or if impairments in these processes lead to alexithymia. What can be said is that there is an association between those emotional variables and alexithymia. Also, alexithymic patients that are doing better in psychotherapy seem to be better of regarding the mediation processes proposed, giving strength to our hypotheses. The non-significant change in good outcome non alexithymic patients in these processes may indicate that in cases without alexithymia the evolution of those processes - specifically awareness and differentiation may not be so central in therapy. Nevertheless, and given the way these clients referred to their change process, emotion dysregulation should not only be measured by the lack of strategies but also by the ability to tolerate emotions.

Two cases presented data that may challenge our model, which point for the need to explore more cases and have other assessment methodologies, such as for example videotaped sessions. Even though non alexithymia cases presented awareness of their avoidance of emotional experiencing, something that was not explicitly described by the alexithymic cases in the study, we cannot affirm that alexithymic patients do not have this awareness. They did not mention it, but this does not mean is not there. Case 11, showed awareness of not expressing emotions, so being aware of is functioning, also in relation to others. The problem seemed more related with some ego sintony with this functioning, which may be more related to personality characteristics rather than alexithymia.

Considering our qualitative data, it should be noted that the richness of these therapeutic processes may had generated more domains and themes. Nevertheless, our goal was to identify aspects that would better describe change in alexithymic cases. A major limitation of this study is assessing alexithymia using self reports. Even though TAS-20 is a worldwide used measure of alexithymia and its version for the Portuguese population presented good psychometric properties, some critics have been made in assessing alexithymia with self-reports, given the difficulties in awareness associated with this condition. A research wishing to study the alexithymia construct would become richer if included several measures of the construct, such as an alexithymia interview (e.g., Toronto Structured Interview for Alexithymia, TSIA, Bagby, Taylor, Parker, \& Dickens, 2006). Our data, considering the differential impact in the different alexithymia factors, point to the need to, perhaps, considering the differentiated processes rather than the all construct when thinking about the therapeutic process. More research is needed to better understand emotional processing evolution with alexithymic patients in psychotherapy and what contributes to that change. Although the research was focused on the processes, the fluctuations in the mediation variables studied would have been better under- stood in full therapies. Not all of the cases in this study were completed therapies and follow-ups would have helped in better understanding those processes evolution and their association with alexithymia and severity of symptoms. We believe that more research is needed on this matter and we hope this study stimulates further investigation on alexithymia in psychotherapy.

\section{References}

Bagby, R. M., Parker, J. D., \& Taylor, G. J. (1994). The TwentyItem Toronto Alexithymia Scale - I. Item selection and crossvalidation of the factor structure. Journal of Psychosomatic Research, 38, 23-32. doi:10.1016/0022-3999(94)90005-1

Bagby, R. M., Taylor, G. J., Parker, J. D., \& Dickens, S. E. (2006). The development of the Toronto structured interview for alexithymia: item selection, factor structure, reliability and concurrent validity. Psychotherapy and Psychosomatics, 75, 25-39. doi: 10.1159/000089224

Berthoz, S., Pouga, L, \& Wessa, M. (2011). Alexithymia from the social neuroscience perspective. In: J. Decety \& J. Cacioppo (Eds.) The Handbook of Social Neuroscience (pp. 906-934). New York, NY: Oxford University Press. doi: 10.1093/oxfordhb/9780195342161.013.0060

Braun, V. \& Clarke, V. (2006) Using thematic analysis in psychology. Qualitative Research in Psychology, 3, 77-101.

Canavarro, M. C. (1999). Inventário de sintomas psicopatológicos (BSI) [Brief Symptoms Inventory (BSI)]. In M. R. Simões, M. M. Gonçalves, \& L. S. Almeida (Eds.), Testes e provas psicológicas em Portugal [Tests and psychological instruments in Portugal] (vol. 2, pp. 87-94). Braga, Portugal: APPORT/SHO.

Christensen, L., \& Mendoza, J. L. (1986). A method of assessing change in a single subject: An alteration of the RC index. Behavior Therapy, 17, 305-308. doi: 10.1016/S00057894(86)80060-0

Derogatis, L. R. (1993). Brief symptom inventory: Administration, scoring, and procedures manual. Minneapolis, MN: National Computer Systems, Inc.

Elliot, R., \& Shapiro, D. A. (1992). Client and therapist as analyst of significant events. In S.G. Toukmanian \& D.L. Rennie (Eds.), Psychotherapy process research. Pragmatic and narrative approaches (pp. 163-186). Newbury Park, CA: Sage.

Evans, C., Margison, F., \& Barkham, M. (1998). The contribution of reliable and clinically significant change methods to evidence-based mental health. Evidence Based Mental Health, 1, 70-72. doi: 10.1136/ebmh.1.3.70

Gratz, K. \& Roemer L. (2004). Multidimensional assessment of emotion regulation and dysregulation: Development, factor structure, and initial validation of the difficulties in emotion regulation scale. Journal of Psychopathology and Behavioral assessment, 26: 41-54. doi: 10.1023/B:JOBA. 0000007455.08539 .94

Hanson, W. E., Creswell, J. W., Clark, V. L. P., Petska, K. S., \& Creswell, J. D. (2005). Mixed methods research designs in counseling psychology. Journal of Counseling Psychology, 52, 224-235. doi: 10.1037/0022-0167.52.2.224

Jacobson, N. S., \& Truax, P. (1991). Clinical significance: A statistical approach to defining meaningful change in psychotherapy research. Journal of Consulting and Clinical Psychology, 59, 12-19. doi: 10.1037//0022-006X.59.1.12 245 
Jacobson, N. S., Follette, W. C., \& Revenstorf, D. (1984). Psychotherapy outcome research: Methods for reporting variability and evaluating clinical significance. Behavior Therapy, 15, 336-352. http://dx.doi.org/10.1016/S00057894(84)80002-7

Kang, S. \& Shaver, P. (2004). Individual differences in emotional complexity: their

psychological implications. Journal of Personality, 72, 687-726.

Krystal, H. (1979). Alexithymia and psychotherapy. American Journal of Psychotherapy, 33, 17-31.

Leweke, F. Bausch, S. Leichsenring, F. Walter, B. \& Stingl, M, (2009). Alexithymia as a predictor of outcome of psychodynamically oriented inpatient treatment. Psychotherapy Research, 19, 323-31. doi: 10.1080/10503300902870554

Lincoln, Y. S., \& Guba, E. G. (1986). But is it rigorous? Trustworthiness and authenticity in naturalistic evaluation. New Directions for Evaluation, 30, 73-84. doi:10.1002/ev.1427

McCallum, M., Piper, W. E., Ogrodniczuk, J. S., \& Joyce, A. S. (2003). Relationships among psychological mindedness, alexithymia, and outcome in four forms of short-term psychotherapy. Psychology and Psychotherapy: Theory, Research and Practice, 76, 133-144. doi: 10.1348/147608303765951177

Ogrodniczuk, J. S., Piper, W. E., \& Joyce, A. S. (2004). Alexithymia as a predictor of residual symptoms in depressed patients who respond to short-term psychotherapy. American Journal of Psychotherapy, 58, 150-161.

Ogrodniczuk, J. S., Piper, W. E., \& Joyce, A. S. (2005). The negative effect of alexithymia on the outcome of group therapy for complicated grief: What role might the therapist play? Comprehensive Psychiatry, 46, 206-213. doi: 10.1016/j. comppsych.2004.08.005

Ogrodniczuk, J. S., Piper, W. E., \& Joyce, A. S. (2011). Effect of alexithymia on the process and outcome of psychotherapy: A programmatic review. Psychiatry Research 190, 4348. doi: 10.1016/j.psychres.2010.04.026

Ogrodniczuk, J. S., Piper, W. E., Joyce, A. S. \& Abbass, A. A. (2009). Alexithymia and treatment preferences among psychiatric outpatients. Psychotherapy and Psychosomatics 78, 383-384. doi: 10.1159/000235981

Ogrodniczuk, J. S., Sochting, I., Piper, W. E., Joyce, A. S. (2012). A naturalistic study of alexithymia among psychiatric outpatients treated in an integrated group therapy program. Psychology and Psychotherapy: Theory, Research and Practice, 85, 278-291. doi: 10.1111/j.2044-8341.2011.02032.x

Pandey, R., Saxena, P., Dubey, A. (2011). Emotion regulation difficulties in alexithymia and mental health. Europe's Journal of Psychology, 7, 604-623. doi: 10.5964/ejop.v7i4.155

Petterson, R. (2004). Nameless desire: Alexithymia and the Anoretic Patient. The American Journal of Psychoanalysis, 64, 77-90.

Prazeres, N., Parker, J. D., \& Taylor, G. J. (2000). Adaptação Portuguesa da Escala de Alexitimia de Toronto de 20 Itens (TAS-20) [Portuguese adaptation of the 20- item Toronto
Alexithymia Scale (TAS-20).] Revista Iberoamericana de Diagnóstico e Avaliação Psicológica, 9, 9-21.

Silva, A.N. Vasco, A.B.V. \& Watson, J.C. (2013). Quando o cliente pensa que não sente e sente o que não pensa: Alexitimia e Psicoterapia [When the client think he does not feel and feels what he does not think: alexithymia and psychotherapy] Análise Psicológica, 2, 1-15.

Silva, A. N., Vasco. A. B. \& Watson, J.C. (2017). Alexithymia and emotional processing: a mediation model. Journal of Clinical Psychology, 73, 1196-1205.

Swiller, H. I. (1988). Alexithymia: Treatment Utilizing Combined Individual and Group Psychotherapy. International Journal of Group Psychotherapy, 38, 47-61.

Tacon, A. (2001). Alexithymia: a challenge for mental health nursing practice. Australian and New Zealand Journal of Mental Health Nursing, 10, 229-235. doi: 10.1046/j.14400979.2001.00215.x

Taylor, G. J. (1984a). Alexithymia: Concept, Measurement, and Implications for treatment. The American Journal of Psychiatry, 141, 725-732.

Taylor, G. J. (1984b). Psychotherapy with the boring patient. Canadian Journal of Psychiatry, 29, 217-222.

Taylor, G. J., Bagby, R. M., \& Parker, J. D. A (1997). Disorders of affect regulation: Alexithymia in medical and psychiatric illness. Cambridge: Cambridge University Press. doi: 10.1017/CBO9780511526831

Uzun, Ö. (2003). Alexithymia in male alcoholics: study in a Turkish sample. Comprehensive Psychiatry, 44, 435-446.

Vaz, F. M. (2009). Diferenciação e regulação emocional na idade adulta: Tradução e validação de dois instrumentos de avaliação para a população portuguesa [Emotional regulation and differentiation in adulthood: validation of two instruments for the portuguese population]. (Unpublished master's thesis). Faculdade de Psicologia da Universidade do Minho, Minho, Portugal.

Vaz, F. M., Vasco, A. B., Greenberg, L., \& Vaz, J. M. (2010). Avaliação do processamento emocional em psicoterapia [Evaluation of emotional processing in psychotherapy] In C. Nogueira, I. Silva, L. Lima, A.T. Almeida, R. Cabecinhas, R. Gomes, C. Machado, A. Maia, A. Sampaio, M. C. Taveira, (Eds.) Conference Proceedings of the VII National symposium of psychology research, Braga, Portugal.

Wise, T. N., Mann, L. S., \& Hill, B. (1990). Alexithymia and depressed mood in the psychiatric patient. Psychotherapy and Psychosomatics, 54, 26-31. doi: 10.1159/000288373

Zeitlan, S. B., \& Mcnally, R. J. (1993). Alexithymia and anxiety sensitivity in panic disorder and obsessive-compulsive disorder. American Journal of Psychiatry, 150, 658-660.

Zlotnick, C., Mattia, J., \& Zimmerman, M. (2001). The relationship between posttraumatic stress disorder, childhood trauma and alexithymia in an outpatient sample. Journal of Traumatic Stress, 14, 177-188. doi: 10.1023/A:1007899918410 